\title{
Perovskite-Type Oxyfluoride Phases in the $\mathrm{ABO}_{3}-\mathrm{BaLiF}_{3}$ Systems $(\mathrm{A}=\mathrm{Ba}, \mathrm{Ca}$ and $\mathrm{B}=\mathrm{Ti}, \mathrm{Zr}$ )
}

\author{
Hiroshi YAMAMURA, Namiko OKITSU and Katsuyoshi KAKINUMA \\ Department of Material and Life Chemistry, Faculty of Engineering, Kanagawa University, \\ 3-27-1, Rokkakubashi, Kanagawa-ku, Yokohama-shi 221-8686
}

\author{
$\mathrm{ABO}_{3}-\mathrm{BaLiF}_{3}$ におけるペロブスカイト型酸フッ化物相（A= Ba, Ca, B = Ti, $\mathrm{Zr} ）$ \\ 山村＼cjkstart博·興津奈弥子·柿沼克良 \\ 神奈川大学工学部物質生命化学科, 221-8686 横浜市神奈川区六角橋 3-27-1
}

\begin{abstract}
Perovskite-type oxyfluoride systems, $\mathrm{ABO}_{3}-\mathrm{BaLiF}_{3}(\mathrm{~A}=\mathrm{Ba}, \mathrm{Ca}$ and $\mathrm{B}=\mathrm{Ti}, \mathrm{Zr})$ were investigated. In the $\mathrm{Ba}\left(\mathrm{Ti}_{1-x} \mathbf{L i}_{x}\right) \mathbf{O}_{3(1-x)} \mathbf{F}_{3 x}$ system, cubic phases appeared in the range, $0.2 \leqq x \leqq 0.4$. In the $\left(\mathrm{Ca}_{1-x} \mathrm{Ba}_{x}\right)\left(\mathrm{Zr}_{1-x} \mathbf{L i}_{x}\right)$ $\mathrm{O}_{3(1-x)} \mathrm{F}_{3 x}$ system, orthorhombic phases different from $\mathrm{CaZrO}_{3}$ appeared in the range, $0.4 \leqq x \leqq 0.5$. The lattice volumes of the new phases were larger than those of the respective end-members. On the other hand, the $\mathrm{Ca}_{1-x} \mathrm{Ba}_{x} \mathrm{Ti}_{1-x} \mathrm{Li}_{x} \mathrm{O}_{3(1-x)} \mathrm{F}_{3 x}$ samples showed two phases of $\mathrm{CaTiO}_{3}$ and $\mathrm{BaLiF}_{3}$, of which lattice constants were almost independent of the composition.

[Received April 19, 2006; Accepted October 19, 2006]
\end{abstract}

Key-words : Oxyfluoride, Perovskite-type structure, Solid solution

\section{Introduction}

Though many perovskite-type oxides have been synthesized, there are only few reports concerning perovskite-type oxyfluorides. Benziada and Claverie $^{1)}$ tried to add $\mathrm{CaF}_{2}-4 \mathrm{LiF}$ to $\mathrm{BaTiO}_{3}$ in order to revise the sintering behavior and the dielectric properties. Benziada and Kermoun ${ }^{2}$ have reported that an orthorhombic phase having a $\mathrm{NaNbO}_{3}$-type structure was obtained by firing $(1-x) \mathrm{SrTiO}_{3}+x \mathrm{SrF}_{2}+x \mathrm{LiF}(0.03 \leqq x \leqq$ $0.05)$ mixtures at $1223 \mathrm{~K}$ in air. Recently, Benziada ${ }^{3)}$ has found that an orthorhombic phase of $\mathrm{CaTiO}_{3}$ remained up to $x=0.25$ in the $\left(\mathrm{Ca}_{1-x} \mathrm{Sr}_{x}\right)\left(\mathrm{Ti}_{1-x} \mathrm{Li}_{x}\right) \mathrm{O}_{3-3 x} \mathrm{~F}_{3 x}$ system.

On the other hand, many oxyfluorides having a fluoriterelated structure have been reported in relation with ionic conduction. Esaka et al. ${ }^{4}$ reported LaOF-type phase in a $\mathrm{La}_{2} \mathrm{O}_{3}-\mathrm{MgF}_{2}$ system. Takashima et al. ${ }^{5)-7)}$ have studied the crystal structure and ionic conductivity of binary rare-earth metal oxyfluorides.

In the present study, existing phases were investigated in the perovskite-type oxyfluoride systems, $\mathrm{ABO}_{3}-\mathrm{BaLiF}_{3}(\mathrm{~A}=\mathrm{Ba}$, $\mathrm{Ca}$ and $\mathrm{B}=\mathrm{Ti}, \mathrm{Zr}$ ).

\section{Experimental procedures}

All the samples for the $(1-x) \mathrm{ABO}_{3}-x \mathrm{BaLiF}_{3}$ system were prepared by a solid-state reaction $(\mathrm{A}=\mathrm{Ba}, \mathrm{Ca}$ and $\mathrm{B}=\mathrm{Ti}$, $\mathrm{Zr}) . \mathrm{BaCO}_{3}$ (99.9\%, Wako Chem. Co.), $\mathrm{CaCO}_{3}$ (99.9\%, Wako Chem. Co.), $\mathrm{TiO}_{2}$ (anatase type) (99.9\%, Wako Chem. Co.) and $\mathrm{ZrO}_{2}$ (99.9\%, Tosoh Co.) were used as starting materials for the corresponding perovskite-type oxides. $\mathrm{BaLiF}_{3}$ was prepared by firing the mixed powders of $\mathrm{BaF}_{2}$ (99.9\%, Wako Chem. Co.) and $\operatorname{LiF}$ (98\%, Wako Chem. Co.) at $973 \mathrm{~K}$ for $10 \mathrm{~h}$ under the Ar gas flow $\left(200 \mathrm{dm}^{3}\right.$ $\min ^{-1}$ ), before the preparation of the solid solution samples. The powder compacts of the starting materials for the perovskite oxide and $\mathrm{BaLiF}_{3}$ were placed into a powder-bed which has the same composition as the compact sample, and then calcined at $873 \mathrm{~K}$. After regrinding the calcined samples, the powder compacts were fired at $1073-1273 \mathrm{~K}$ for $10 \mathrm{~h}$ in the same powder bed under the Ar gas flow. In order to prevent from vaporization of $\mathrm{Li}$ and $\mathrm{F}$, the firing procedures were
Table 1. Firing Conditions of the $\left(\mathrm{Ca}_{1-x} \mathrm{Ba}_{x}\right)\left(\mathrm{Zr}_{1-x} \mathrm{Li}_{x}\right) \mathrm{O}_{3(1-x)} \mathrm{F}_{3 x}$ System

\begin{tabular}{ccc}
\hline Composition $(x)$ & Calcination & Sintering \\
\hline 0.0 & $1273 \mathrm{~K}-10 \mathrm{~h}$ & $1573 \mathrm{~K}-10 \mathrm{~h}$ \\
0.2 & $873 \mathrm{~K}-10 \mathrm{~h}$ & $1173 \mathrm{~K}-10 \mathrm{~h}$ \\
0.4 & $873 \mathrm{~K}-10 \mathrm{~h}$ & $1073 \mathrm{~K}-10 \mathrm{~h}$ \\
0.5 & $973 \mathrm{~K}-10 \mathrm{~h}$ & $1073 \mathrm{~K}-10 \mathrm{~h}$ \\
0.6 & $873 \mathrm{~K}-10 \mathrm{~h}$ & $1073 \mathrm{~K}-10 \mathrm{~h}$ \\
0.8 & $873 \mathrm{~K}-10 \mathrm{~h}$ & $973 \mathrm{~K}-10 \mathrm{~h}$ \\
1.0 & $823 \mathrm{~K}-10 \mathrm{~h}$ & $973 \mathrm{~K}-10 \mathrm{~h}$ \\
\hline
\end{tabular}

Remarks: The samples containing $\mathrm{Li}$ and $\mathrm{F}$ were fired under Ar gas flow.

carried out at lower temperatures than their vaporization temperature determined from thermogravimetry (TG) and mass spectrometry (MS) for the calcined powders. The typical firing conditions are summarized in Table 1 for the $\left(\mathrm{Ca}_{1-x} \mathrm{Ba}_{x}\right)$ $\left(\mathrm{Zr}_{1-x} \mathrm{Li}_{x}\right) \mathrm{O}_{3(1-x)} \mathrm{F}_{3 x}$ samples. The samples of the other systems were also fired under the similar firing conditions.

Powdered samples were characterized by X-ray diffractometry (XRD) (model: RAD-A, Rigaku Co.) with monochromated $\mathrm{Cu} \mathrm{K} \alpha$ radiation. The lattice constants were determined by a least square method, using Si powder as an external standard. The Rietveld refinement for the powder XRD patterns of $\mathrm{BaLiF}_{3}$ was carried out using the RIETAN-2000 program ${ }^{8)}$ at room temperature. X-ray photoelectron spectrometry (XPS) was applied in order to confirm the existence of $\mathrm{F}$ and Li. $F$ content for the typical samples was estimated from the XPS data. As chemical analysis has not been carried out, the nominal composition $(x)$ was presented in this paper. 
a)

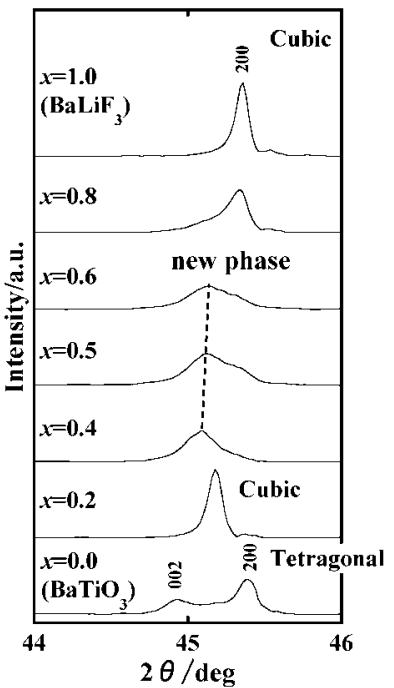

b)

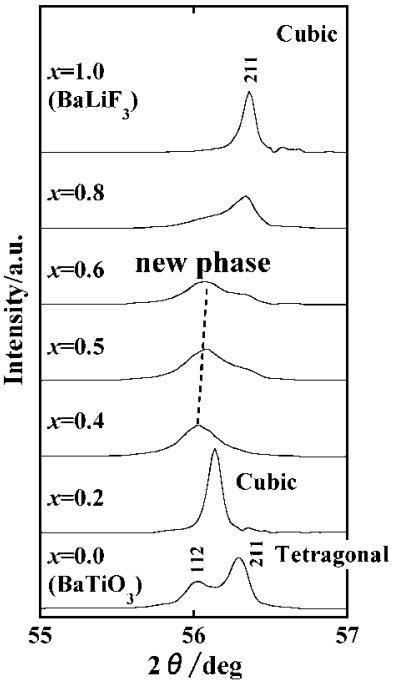

Fig. 1. XRD patterns for the $\mathrm{Ba}\left(\mathrm{T}_{1-x} \mathrm{Li}_{x}\right) \mathrm{O}_{3(1-x)} \mathrm{F}_{3 x}$ system in the $2 \theta$ ranges, a) $44-46^{\circ}$ and b) $55-57^{\circ}$.

\section{Results and discussion}

(a) $\mathrm{BaTiO}_{3}-\mathrm{BaLiF}_{3}$ system

$\mathrm{BaTiO}_{3}$ was a tetragonal perovskite-type phase $(a=0.3995$, $\left.c=0.4031 \mathrm{~nm}, V=0.06433 \mathrm{~nm}^{3}\right)$ and that $\mathrm{BaLiF}_{3}$ was a cubic perovskite-type one $\left(a=0.3995 \mathrm{~nm}, V=0.06377 \mathrm{~nm}^{3}\right)$. These observed lattice parameters agreed well with the reported values. ${ }^{9), 10)}$ The lattice volume of $\mathrm{BaTiO}_{3}$ was close to that of $\mathrm{BaLiF}_{3}$. Furthermore, the Rietveld refinement confirmed that $\mathrm{BaLiF}_{3}$ has $\mathrm{Ba}^{2+}$ at $\mathrm{A}$ site and $\mathrm{Li}^{+}$at $\mathrm{B}$ site in $\mathrm{ABF}_{3}$ perovskite structure with the space group of $P m \overline{3} m$. Traces of oxygen were detected for $\mathrm{BaLiF}_{3}$ by XPS.

$\mathrm{BaTiO}_{3}$ changed to a cubic phase at $x=0.2$ and then a set of new broad diffraction peaks appeared at $x=0.4$, as shown in Fig. 1. The new peaks were indexed on the basis of the cubic perovskite lattice. The estimated lattice parameter of $x=0.4$ was $a=0.4017 \mathrm{~nm}$. The observed and calculated $d$-values of the cubic phase are given in Table 2. Though the lattice volume of $\mathrm{BaTiO}_{3}$ was close to that of $\mathrm{BaLiF}_{3}$, the lattice volume of $x=0.4\left(0.06482 \mathrm{~nm}^{3}\right)$ was larger than their values. Two phases composing of the new cubic phase and $\mathrm{BaLiF}_{3}$ appeared in the composition range, $0.5 \leqq x \leqq 0.8$. The lattice volume of $\mathrm{BaLiF}_{3}$ decreased by increasing the composition $(x)$ (Fig. 2). The broad diffraction peaks of the new cubic phase may originate from a crystal imperfection and/or a compositional fluctuation.

The $F$ contents for the typical samples are summarized in Table 3, where the area intensity of the $F$ peak in XPS was normalized using that of $\mathrm{BaLiF}_{3}(x=1.0)$. Though the $F$ content did not agree completely with the nominal composition, the vaporization of $F$ could be suppressed to a minimum.

\section{(b) $\mathrm{CaZrO}_{3}-\mathrm{BaLiF}_{3}$ system}

Figure 3 shows XRD patterns of the $\left(\mathrm{Ca}_{1-x} \mathrm{Ba}_{x}\right)\left(\mathrm{Zr}_{1-x} \mathrm{Li}_{x}\right)$ $\mathrm{O}_{3(1-x)} \mathrm{F}_{3 x}$ samples. A set of new diffraction peaks appeared at $x=0.4$, suggesting the formation of a new oxyfluoride phase. In the composition range, $0.6 \leqq x \leqq 0.8$, two phases of the oxyfluoride and $\mathrm{BaLiF}_{3}$ appeared. The diffraction peaks of the new phase were tentatively indexed on the basis of the orthorhombic lattice of $\mathrm{CaZrO}_{3}$. Most of the peaks were indexed by the orthorhombic lattice different from $\mathrm{CaZrO}_{3}$, while the peaks having $d=0.3153$ and $0.2012 \mathrm{~nm}$ were not
Table 2. Observed and Calculated $d$-values for the Sample with $x=$ 0.4 in the $\mathrm{Ba}\left(\mathrm{T}_{1-x} \mathrm{Li}_{x}\right) \mathrm{O}_{3(1-x)} \mathrm{F}_{3 x}$ System

\begin{tabular}{|c|c|c|c|}
\hline$h k l$ & Intensity & $d_{0 i s .}(\mathrm{nm})$ & $d_{\text {calc }}(\mathrm{nm})^{*}$ \\
\hline 100 & 17 & 0.4016 & 0.4017 \\
\hline 110 & 100 & 0.2839 & 0.2841 \\
\hline 111 & 38 & 0.2320 & 0.2319 \\
\hline 200 & 46 & 0.2009 & 0.2009 \\
\hline 210 & 17 & 0.1797 & 0.1797 \\
\hline 211 & 54 & 0.1640 & 0.1640 \\
\hline 220 & 28 & 0.1421 & 0.1420 \\
\hline 300 & 8 & 0.1339 & 0.1339 \\
\hline 310 & 19 & 0.1271 & 0.1270 \\
\hline
\end{tabular}

Note 1) $d_{c: a l c}$. was calculated by use of lattice constant,

$$
a=0.4017 \mathrm{~nm} \text {. }
$$

2) Standard deviation between $d_{\mathrm{ob}}$, and $d_{\text {calc. was }} 0.0001 \mathrm{~nm}$.

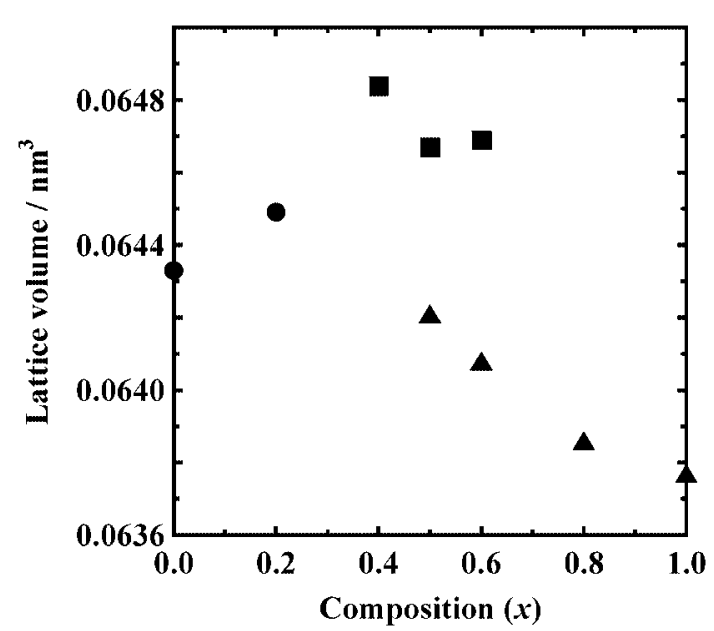

Fig. 2. Lattice volume as a function of composition $(x)$ in the $\mathrm{Ba}\left(\mathrm{T}_{1-x} \mathrm{Li}_{x}\right) \mathrm{O}_{3(1-x)} \mathrm{F}_{3 x}$ system; $\mathrm{BaTiO}_{3}(\mathbf{)})$, new cubic phase and $\mathrm{BaLiF}_{3}(\mathbf{\Lambda})$ phases.

indexed. The lattice parameters estimated for $x=0.5$ were $a=0.5964, b=0.8369$ and $c=0.5941 \mathrm{~nm}\left(V=0.2965 \mathrm{~nm}^{3}\right.$ for $Z=4)$. The observed and calculated $d$-values of $x=0.5$ are given in Table 4, where the $d$-values agreed with each other. The lattice volume of the new phase was also larger than those of $\mathrm{CaZrO}_{3}\left(V=0.258 \mathrm{~nm}^{3}\right.$ for $\left.Z=4\right)$ and $\mathrm{BaLiF}_{3}(V=0.2554$ $\mathrm{nm}^{3}$ for $\left.Z=4\right)$, as seen in the $\mathrm{Ba}\left(\mathrm{Ti}_{1-x} \mathrm{Li}_{x}\right) \mathrm{O}_{3(1-x)} \mathrm{F}_{3 x}$ system. On the other hand, the lattice volume of $x=0.5$ was close to that of $\mathrm{BaZrO}_{3}\left(V=0.2948 \mathrm{~nm}^{3}\right.$ for $\left.Z=4\right)$. Since the new phase might have been corresponded to $\mathrm{BaZrO}_{3}, \mathrm{Ba}\left(\mathrm{Zr}_{1-x} \mathrm{Li}_{x}\right)$ $\mathrm{O}_{3(1-x)} \mathrm{F}_{3 x}$ samples were synthesized. The XRD of $x=0.5$ showed the mixed phases composing of $\mathrm{BaZrO}_{3}$ and $\mathrm{BaLiF}_{3}$. The new orthorhombic phase of $x=0.5$ in the $\left(\mathrm{Ca}_{1-x} \mathrm{Ba}_{x}\right)$ $\left(\mathrm{Zr}_{1-x} \mathrm{Li}_{x}\right) \mathrm{O}_{3(1-x)} \mathrm{F}_{3 x}$ system could be the oxyfluoride. The $F$ contents in the $\mathrm{CaZrO}_{3}-\mathrm{BaLiF}_{3}$ system are also given in Table 3. 
Table 3. $\quad F$ Content Estimated from XPS Peaks in the $\mathrm{Ba}\left(\mathrm{T}_{1-x} \mathrm{Li}_{x}\right)$ $\mathrm{O}_{3(1-x)} \mathrm{F}_{3 x}$ and $\left(\mathrm{Ca}_{1-x} \mathrm{Ba}_{x}\right)\left(\mathrm{Zr}_{1-x} \mathrm{Li}_{x}\right) \mathrm{O}_{3(1-x)} \mathrm{F}_{3 x}$

\begin{tabular}{|c|c|c|c|}
\hline \multirow[t]{2}{*}{$\operatorname{comp} .(x)$} & \multirow{2}{*}{$\begin{array}{c}\text { calc. value } \\
(3 x)\end{array}$} & \multicolumn{2}{|r|}{ obs. value } \\
\hline & & $\mathrm{Ba}\left(\mathrm{T}_{1-x} \mathrm{Li}_{x}\right) \mathrm{O}_{3:\{1-x\}} \mathrm{F}_{\mathrm{ar}}$ & $\left(\mathrm{Ca}_{-x} \mathrm{Ba}_{x}\right)\left(\mathrm{Zr}_{1-x} \mathrm{Li}_{-}\right) \mathrm{O}_{3,1<x} \mathrm{~F}_{3 x}$ \\
\hline 0.2 & 0.6 & 0.57 & 0.90 \\
\hline 0.5 & 1.5 & 1.3 & 1.7 \\
\hline 0.8 & 2.4 & 2.5 & 2.7 \\
\hline
\end{tabular}

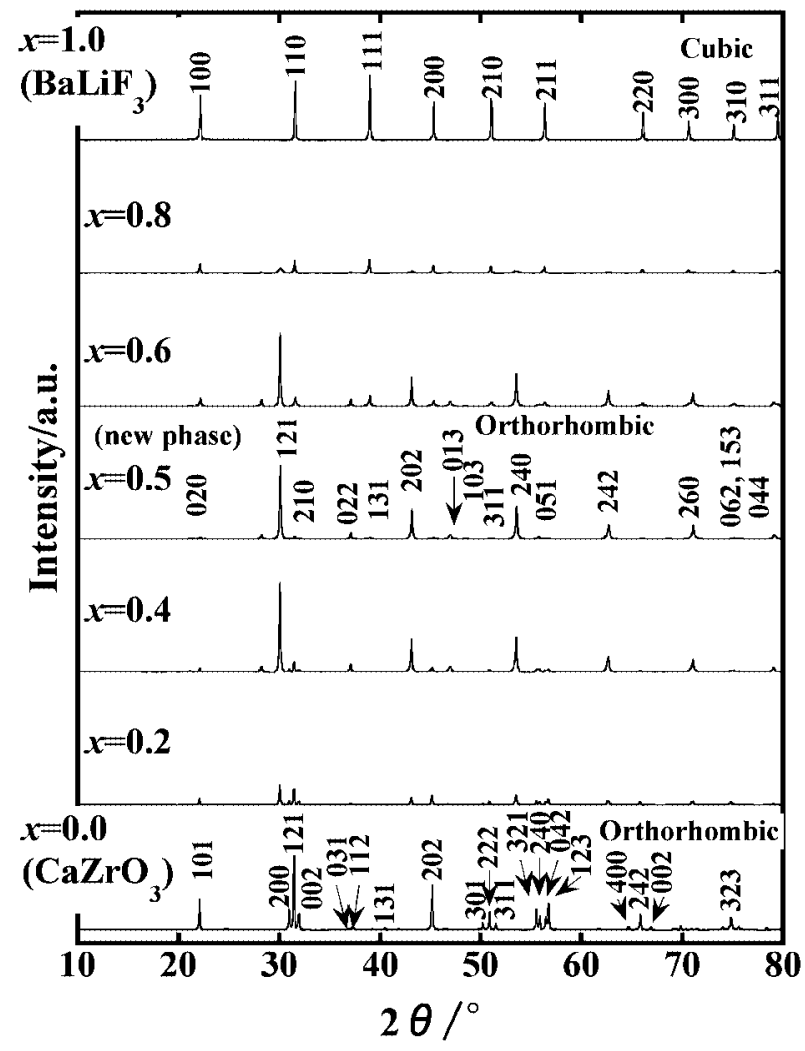

Fig. 3. XRD patterns for the $\left(\mathrm{Ca}_{1-x} \mathrm{Ba}_{x}\right)\left(\mathrm{Zr}_{1-x} \mathrm{Li}_{x}\right) \mathrm{O}_{3(1-x)} \mathrm{F}_{3 x}$ system. The peaks of $x=0.5$ were indexed by the orthorhombic lattice.

(c) $\mathrm{CaTiO}_{3}-\mathrm{BaLiF}_{3}$ system

There existed two phases of $\mathrm{CaTiO}_{3}$ and $\mathrm{BaLiF}_{3}$ in the composition range, $0.2 \leqq x \leqq 0.8$ of in the system $\left(\mathrm{Ca}_{1-x} \mathrm{Ba}_{x}\right)$ $\left(\mathrm{Ti}_{1-x} \mathrm{Li}_{x}\right) \mathrm{O}_{3(1-x)} \mathrm{F}_{3 x}$. The lattice volumes of $\mathrm{CaTiO}_{3}$ and $\mathrm{BaLiF}_{3}$ were almost independent of the composition (Fig. 4).

\section{Summary}

(1) The cubic perovskite phase was obtained for $x=0.4$ in the $\mathrm{Ba}\left(\mathrm{Ti}_{1-x} \mathrm{Li}_{x}\right) \mathrm{O}_{3(1-x)} \mathrm{F}_{3 x}$ system, of which lattice parameter $(a=0.4017 \mathrm{~nm})$ was larger than those of the end-members. (2) The new orthorhombic phase having lattice parameters, $a=0.5964, b=0.8369$ and $c=0.5941 \mathrm{~nm}$ was observed at $x=0.5$ in the $\left(\mathrm{Ca}_{1-x} \mathrm{Ba}_{x}\right)\left(\mathrm{Zr}_{1-x} \mathrm{Li}_{x}\right) \mathrm{O}_{3(1-x)} \mathrm{F}_{3 x}$ system, of which lattice volume was also larger than those of the endmembers. (3) There was no solid solution in the $\mathrm{CaTiO}_{3}-$ $\mathrm{BaLiF}_{3}$ system.

Acknowledgements This study was supported by the Scientific Frontier Research Project from the Ministry of Education, Science, Sport and Culture, Japan.
Table 4. Observed and Calculated $d$-values for the Sample with $x=$ 0.5 in the $\left(\mathrm{Ca}_{1-x} \mathrm{Ba}_{x}\right)\left(\mathrm{Zr}_{1-x} \mathrm{Li}_{x}\right) \mathrm{O}_{3(1-x)} \mathrm{F}_{3 x}$ System

\begin{tabular}{|c|c|c|c|}
\hline$h k l$ & Intensity & $d_{\text {ch.. }}(\mathrm{nm})$ & $d_{\text {calc. }}(\mathrm{nm})^{*}$ \\
\hline 020 & 1 & 0.4189 & 0.4184 \\
\hline 121 & 100 & 0.2965 & 0.2968 \\
\hline 012 & 1 & 0.2829 & 0.2809 \\
\hline 220 & 8 & 0.2420 & 0.2421 \\
\hline 131 & $<1$ & 0.2326 & 0.2325 \\
\hline 202 & 62 & 0.2096 & 0.2105 \\
\hline 310 & 5 & 0.1933 & 0.1927 \\
\hline 301 & $<1$ & 0.1875 & 0.1880 \\
\hline 042 & 49 & 0.1711 & 0.1713 \\
\hline 150 & 2 & 0.1617 & 0.1611 \\
\hline 242 & 22 & 0.1482 & 0.1484 \\
\hline 060 & $<1$ & 0.1398 & 0.1395 \\
\hline 421 & $<1$ & 0.1365 & 0.1363 \\
\hline 161 & 18 & 0.1326 & 0.1324 \\
\hline 062 & 1 & 0.1264 & 0.1263 \\
\hline 260 & $<1$ & 0.1256 & 0.1263 \\
\hline 351 & $<1$ & 0.1252 & 0.1250 \\
\hline 440 & $<1$ & 0.1210 & 0.1211 \\
\hline & & & \\
\hline
\end{tabular}

Note 1) $d_{\text {calc }}$ was calculated using the lattice constant, $a=0.5941$, $b=0.8369, c=0.5964 \mathrm{~nm}$.

2) Standard deviation between $d_{\mathrm{obs}, \text { and }} d_{\text {cakc }}$ was $0.0006 \mathrm{~nm}$.

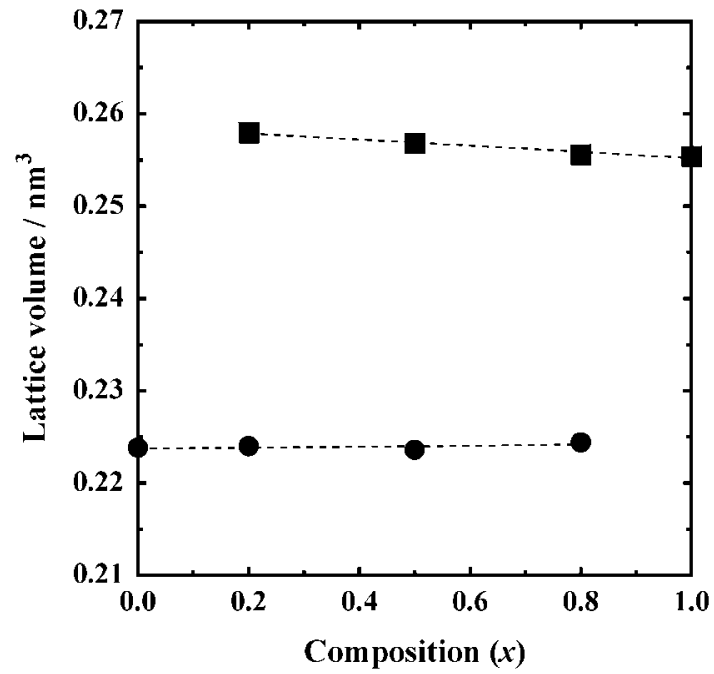

Fig. 4. Lattice volume as a function of composition $(x)$ in the $\left(\mathrm{Ca}_{1-x} \mathrm{Ba}_{x}\right)\left(\mathrm{Ti}_{1-x} \mathrm{Li}_{x}\right) \mathrm{O}_{3(1-x)} \mathrm{F}_{3 x}$ system; $\mathrm{CaTiO}_{3}$ (O) and $\mathrm{BaLiF}_{3}$ phases.

\section{References}

1) Taibi-Benziada, L. and Claverie, J., Ferroelectrics, Vol. 189, pp. 129-138 (1996).

2) Taibi-Benziada, L. and Kermoun, H., J. Fluorine Chem., Vol. 96, pp. 25-29 (1999).

3) Taibi-Benziada, L., Solid State Phenomena, Vol. 90-91, pp. 433-438 (2003) 
4) Esaka, T., Aoki, A. and Iwahara, H., J. Appl. Electrochem., Vol. 16, pp. 259-264 (1986).

5) Takashima, M., Yonezawa, S. and Ukuma, Y., J. Fluorine Chem., Vol. 87, pp. 229-234 (1998).

6) Takashima, M., Yonezawa, S., Tanioka, T., Nakajima, Y. and Leblanc, M., Solid State Sci., Vol. 2, pp. 71-76 (2000).
7) Takashima, M., Yonezawa, S. and Leblanc, M., Solid State Ionics, Vol. 154-155, pp. 547-553 (2002).

8) Izumi, F. and Ikeda, T., Mater. Sci. Forum, Vol. 321-324, pp. 198-203 (2000).

9) JCPDS, 5-0626.

10) JCPDS, 18-0715. 